\title{
A efêmera utopia dos escravos de Nueva Granada: 0 caso do palenque de Cartago
}

\section{The ephemeral utopia of Nueva Granada slaves: the Cartago palenque case}

\section{Pablo Rodríguez}

D o século XVI ao XIX o continente americano viveu uma história inédita e um dos seus aspectos mais peculiares foi o sistema escravista, sistema que, da América do $\mathrm{N}$ orteao $\mathrm{C}$ hile, edas Antilhas e Brasil até as costas peruanas, cobriu variedade dereal idades econômicas, sociaiseculturais. ${ }^{1} \mathrm{Em}$ todos estes lugares também, como reação aos duros ritmos de trabalho, a violência exercida, a pobreza a que se submetia, foram conhecidas rebeliões elevantes de escravos, além de fugas individuais, de casais e pequenos grupos. Em poucos casos se tratou, como no Brasil ou no Suriname, do estabelecimento de sistemas alternativos de sociedadee de autênticas ameaçasà ordem colonial. Tratou-sesim, na maioria das vezes, de protestos ereclamações contra 0 abandono dos senhores. As leis que lhes ampararam foram tardias epouco reconhecidas. ${ }^{2}$ Assim, o interesse em trocar de senhor ou formar um casal com quem se desejasseeram aspirações pouco alcan çáveis, apesar de que antigas leis assim o considerassem.

A magnitude do palenque de C artago épequena, se comparada com o quilombo dos Palmares ou o palenque de San Basilio. ${ }^{3}$ Tanto pela brevidade desua duração, o reduzido número de membros ea ambigüidade de seus propósitos, o palenque de Cartago parece mais uma reação espontânea e emotiva diante das condições de vida a que estavam submetidos os escravos das fazen das. Em sua formação primavam mais as intenções que cada um 
tinha para ajeitar sua vida do que a preparação de um projeto subversivo coletivo, no entanto, seu caso nos ofereceelementos de sumo interesse para refletir sobre a vida cotidiana dos cimarrones. ${ }^{4} \mathrm{Um}$ aspecto importante é 0 de que este grupo era formado por um bom número de pessoas livres (três mulheres eum homem) eque vários queriam consolidar sua vida conjugal impedida pela condição de cativos. Sua devoção esuas cren ças religiosasnos falam de um grupo de escravos integrados culturalmente ao mundo dos brancos, ainda que sua fénão parecesse provocar um estado de resignação. I gualmente, éimportante observar a existência de formas de organização e festejos dos escravos que, como al egorias, Ihes permitiam esboçar um mundo de reconhecimentos próprios. 0 cabildo clandestino por eles formado, e as cerimônias em que se nomeavam vice-reis, governadores, alcaides e outras autoridades, revelam preeminências e hierarquias entre os negros que habitualmentedesconhecemos.

Cartago, fundada em 1540, levou uma existência penosa devido à falta de população indígena em seus arredores. Sua escassa população eeconomia se sustentavam na criação de gado em rústicas fazendas. Foi o descobrimento de ricas minas de ouro na região Pacífica, no início do século XVIII, evento que a converteria em lugar de passagem obrigatória eque, devido a sua proximidade a estes distritos, a transformou em seu principal provedor de carnes eaçúcar. Estefato deu impulso renovado a sua economia, observado principalmentena multiplicação das fazendas degado eno surgimento de trapiches açucareiros trabal had os por uma população escrava em crescimento. Contudo, C artago, em 1785, quando houvea fuga deescravos, era uma vila extremamente simples. Sua arquitetura era muito modesta e a maior parte da população vivia no entorno rural. 0 sescravos, fato notável, não estavam concentrados em poucas mãos. M uitos fazendeiros médios e pequenos possuíam quatro ou cinco escravos, com os que compartilhavam sua vida no campo. ${ }^{5}$ Talvez este fato seja a principal chave para explicar a clemência pedida pelos senhores para os ci marrones de C artago.

N ão obstante, a escravidão neogranadina transcorria em uma permanentetensão. D istintos registros criminais insinuam que os senhores viviam em estado de contínuo temor. Em Reales deM inas del Pacífico, uma região isolada, onde não havia presença de autoridades, os mineiros espanhóis deviam conviver com grupos de escravos numerosos. Ali o medo se convertia 
em obsessão paranóica que, não poucas vezes, terminava em loucura. Convivendo com os escravos, muitos dos quais boçais, os senhores e capatazes brancos temiam que os al imentos que as negras I hes davam estivessem envenenados ou que os cantos que faziam nos domingos fossem um chamado para dar-Ihesmorte. ${ }^{6} \mathrm{~N}$ o Vale do Cauca, a captura, em Cáli, do negro Pablo, em 1772, que havia confessado um suposto plano de fuga e insurreição, provocou uma enorme inquietude entre os fazendeiros. $A$ autenticidade deste movimento nunca se demonstrou, no entanto foi citado como fato grave nos processos posteriores. Ainda que na região não tenham sido freqüentes as mortes desenhores brancos em mãos de seus escravos, parece que o medo de que isso ocorresse era corrente. Pensavam, especialmente, que em qualquer momento podiam vingar os castigos que Ihes infligiam. Por isso, muitos procuravam vendê-los em zonas afastadas do Reino, de onde não pudessem regressar. 0 utros simplesmente esperavam que o cepo ou 0 calabouço, lugares que se fizeram comunsnasfazendas da região, dissuadissem efetivamente toda a pretensão de represália.

O s processos sobre os palenques e quilombos são documentos complexos. Q uando menos, podemos dizer queao longo deles se expressa uma luta deinteresses, os do Estado, dos senhores edos escravos. 0 processo do palenque de Cartago é um destes. Conduzido em primeira instância em Cartago, uma local idade menor e distante da capital, observou uma forte intervenção emanipulação dos senhores. Transladado a Santa Fé, o processo adquiriu outro teor com a intervenção da Audiência. Seria ingênuo ignorar que os interesses em luta conduzem, em ocasiões, à invenção de testemunhos e provas. U ma destas, que explico no texto, é a suposta intenção quetinham os escravos de roubar, violar eassassinar as mulheres brancas da cidade. Convém, portanto, uma leitura cuidadosa, atenta às circunstâncias, incidências e contexto, para descobrir as rupturas e manipulações nestes inquéritos. Assim, este processo, como todos os processos criminais, nos oferece um importantematerial para compreender o complexo processo de decisão da fuga, de sua realização e das efêmeras ilusões de liberdade nascidas no lugar do palenque. 


\section{A aventura da fuga}

Provavelmentefoi ao cair da tarde de 16 deagosto de 1785 quando se juntaram na ramada do trapiche de $D$ om $M$ ariano $M$ atute y $H$ ormaza os escravos que planejavam fugir. D urante meses, escravos de distintos fazendeiros da região haviam considerado o plano de fugir para as montanhas e não eram poucos os que afirmavam estar de acordo. Assim que, impacientes, os que haviam chegado esperaram equando tiveram a certeza de quejá não chegariam outros, iniciaram o percurso seguindo a margem do rio La Vieja atéum lugar chamado Los Cerritos. C aminharam toda a noite, quase sem descanso, atéchegar à casa da índia $\mathrm{M}$ aria, com quem estavam acertados. Esta os manteve ocultos em um bananal durante todo o dia. Foi ali também onde se juntou a eles a negra $M$ anuela com seu filho C ristóbal, que havia chegado no dia anterior. D urante a noite voltaram ao caminho, desta vez guiados por Pedro, um índio deconfiança daíndia M aria. D urante dois dias o grupo caminhou até o Rio do 0 tún, onde o índio Pedro os deixou, indicando o caminho atéas montanhas. Lugares com mata cerrada, impenetráveis, onde presumível e equivocadamente habitavam os índios Cocamas, os quais, por serem inimigos dos brancos, Ihes dariam ajuda.

0 grupo era formado pelo escravo Prudêncio, que se converteu em líder, sua esposa M artina e seu filho M arcos; os escravos Andrés, Juan José, Juan M anuel, Simon, Atanásio de los Santos, M anuela, Cristóbal ePaula; 0 mulato livre Vicente $D$ osaga e as mulatas, também livres, Juana Romero e $M$ aria Avellaneda. Prudêncio, sua mulher, seu filho eo escravo Juan M anuel pertenciam a $D$ om $M$ ariano $M$ atute, enquanto que os demais escravos eram de D om Francisco de C astro, D om Jacinto U sechi, D om Antônio M azuera, D om Simón de Soto e D om Pedro de Aguilar. Todos se empenhavam em trabalhos domésticoseno campo, menosJuana Romero, queera parteiraecostureira, C ristóbal, queera ferreiro, ePrudêncio, queera Capitão deE stância. Foi esta condição que converteu Prudêncio em guia da pequenainsurreição.

Conscientes da importância de assegurar provisões tanto para a fuga como para sua sobrevivência, Prudêncio, Andrés e Atanásio roubaram um terneiro eum porco para sal gar suas carnes. Também levaram sementes de feijão, milho etabaco, queforam dispersando por onde faziam paradas. As 
três semanas que conseguiram permanecer em seu palenque foram ocupadas em levantar cabanasque seriam destinadas a grupos familiares, cultivar, caçar, pescar e cozinhar. D urantea noiterezavam, conversavam sobreplanos futuros e dormiam em casais.

O lugar escolhido para estabelecer o palenqueera impenetrável eideal para resistir a qual quer ataque. Segundo a descrição dos soldados comissionados era "a modelo de fuerte". Para chegar a ele era necessário atravessar vários rios, al guns de águas profundas, atravessar uma mata cerrada, subir alguns degraus atéchegar a uma clareira que haviam aberto para estabelecerse. Aqueles degraus serviam de defesa, pois, se destruídos, ficaria impossível alcançar aquele ponto. Tanto assim que, como dissera um dos militares: "si ocho dias más hubieran tardado en solicitud de ellos, después ni mil hombres que hubieran ido loshabrían sacado desu fortificación".

A denúncia da fuga dos escravos foi feita por $D$ om $M$ ariano $M$ atute no dia 30 de setembro ao alcaide ordinário de C artago, D om Juan Bautista Sanz y V icuña. D epois desta denúncia se sucederam as dos outros fazendeiros, que, alarmados do fato, se ofereceram eles próprios a participar da captura. D ado que a pequena vila carecia de um corpo de armas, designaram alguns comissionados, "hombresmontaraces", para que reunissem gente suficiente para capturar os fugitivos. Estes e os demais que se juntaram, que formaram um corpo de trinta, eram homens de confiança dosfazendeiros, que lhes forneceram armase alimentos para a empresa. M as somente quando Juan de Rojas, al caideindígena do povoado de Cerritos, viajou a C artago a entregar o lugar exato onde se achavam os escravos que a expedição partiu em sua busca. Fizeram formação na Praça $M$ aior da vila às duas e meia da tarde, quando o al caide leu o bando que os autorizava a que "si no se di esen ni rindiesen lasarmas, y embi stiesen o formaren batalla, den la voz quematen al enemigo, para que los demás desembarazados puedan hacer prisión de los otros, sin permitir peligro, ni pérdida de los fieles y obedientes vasallos que los acompañan". 0 percurso feito pela esquadra foi similar àquele realizado pelos escravos, toda vez que iam guiados pelo delator, o alcaide indígena, que era experienteem percorrer aquelas paragens.

0 propósito da sua fuga não era inventar uma nova cotidianidade. Suas atividades eram as mesmas, só queagoralivres das restrições da escravidão. Para isso se preparavam havia tempos, quando haviam escondido as 
sementes de milho. $\mathrm{N}$ as poucas semanas que conseguiram manter em seu palenquesua vida tinha a rotina própria do povo do campo. Segundo uma disposição de gênero, os homens se ocupavam de cultivar milho e feijão, caçar veados e pescar no rio. Asmulheres assavam carnes, bananas e espigas de milho em uma assadeira que haviam instalado sobre pedras. D urante a noite conversavam e rezavam o rosário, para pedir por suas vidas. Além disso, sabemos que dormiam em casais, ainda que não fosse pelo rito católico. Suas casas, espécie de cabanas, que apenas construíam, permitiriam a organização de cada família e o decoro do povoado. Assim, com dificuldade, a rotina das sociedades livres dos pal enques podiam resumir-se às atividades da época.

Segundo o testemunho dos comissionados, ao chegar ao local, encontraram vários ranchos recém-construídos, emaisadiante um murmúrio de vozes, que descobriram ser dos escravos. 0 s homens se encontravam ocupados em construir um rancho eas mulheres estavam assando plátanos debaixo de uma ramada que haviam erguido. D epois de se dispersarem de tal forma que assegurassem tê-los cercados, J oaquín Suárez gritou mais de vinte vezes que em nome do Rei se rendessem e se entregassem presos. A esta chamada os escravos responderam "jamás", e brandiram machetes e lanças que haviam feito com chonta, um arbusto da região. N o embate, os mais aguerridosforam o negro Andrés, a negra M anuela e o escravo Atanásio. D o combate saíram feridos Atanásio, com um golpe na cabeça, uma ferida no ombro, outra no mamilo direito e em um dedo da mão; Andrée $M$ anuela com distintas contusões na cabeça. O s outros companheiros foram reduzidos ou não opuseram maior resistência. Pouco depois apareceu Prudêncio e o negro Juan M anuel, os quais haviam saído para caçar caititus, um mamífero próprio das quentes terras americanas. Prudêncio não pôde dar um passo quando teve várias armas sobre seu corpo, e Juan $M$ anuel que os enfrentou intensamente, rodeado por vários soldados, recebeu um golpe seco na cabeça que o deixou inconsciente durante um bom tempo. R eduzido eimpotente, Prudêncio maldice: "voto al demonio, quesi yo hubiera estado aquí no noshubieran cogido, porqueo nosotros loshubiéramosmatado o ellosnos habrían acabado". Foi então quando descobriram quefaltavam dois, o escravo Juan José e o livre V icente D osaga, os quais, ao escutarem a algazarra se ocultaram no monte. Uma vez aprisionados, os amarraram e, junto a suas 
armas eescassos bens, foram levadosà prisão deC artago, em meio à comoção do povo.

\section{As razões da fuga}

As confissões, declarações etestemunhos obtidosno processo feito aos escravos e livres que pretenderam estabelecer o palenque de $C$ artago compõem um material de indiscutível interesse. 0 documento revela especialmente todas as tensões do sistema escravista mas, também neste caso, a ansiedade das autoridades por desvelar um autêntico complô. Toda a região do Vale do Rio Cauca, que compreende em seu ponto mais ao norte a Cartago, povoada de fazendas com pequenos trapiches, cultivos e gados, viveram entre as décadas de 1760 e 1780 uma espécie de permanente medo e inquietude sobre possíveis levantes de escravos. $\mathrm{N}$ a verdade, este temor não passava de uma invenção sem nenhuma razão efetiva para existir. Provavel mente estemedo se difundia com a intenção dejustificar a sevíciaeos maus-tratos demuitossenhores.

A fuga dos escravosteve causas precisas, pelas quais os escravos elivres que os acompanharam buscavam escapar das formas insidiosas da escravidão, ainda quetambém de um sistema que impedia a realização pessoal, ou seja, cada um dos participantes na fuga tinha intensas razões para buscar uma nova vida, sem que isso estivesse fundado em um discurso elaborado contra a escravidão. Foi o encontro, provavelmente nada ocasional, destes sujeitos inquietos, que não ocultavam seu mal-estar, o que os uniu para a realização desta incursão cimarrona.

U ma das principais causas expostas pelos escravos para a fuga foi 0 temor de castigo de seus senhores. Vários deles expuseram de forma detaIhada o temor de serem castigados por pequenas faltas cometidas. Escravo de $M$ ariano $M$ atute, de 16 anos de idade, Juan Josédeclarou que temia que seu senhor o castigasse com o chicote por não ter encontrado um cavalo que estava encarregado de buscar. Escravo de D om Pedro de Aguillar e com 30 anos de idade, Simon confessou que havia fugido porque seu amo o tinha ameaçado com cem açoites. Escravo de Jacinto U sechi e de 20 anos de idade, Juan $M$ anuel declarou que seu amo Ihe havia dado vinte e cinco açoites porque lhe mandou ir cedo a C artago enão o fez. Escrava de D om 
Simon de Soto, de 30 anos de idade, Paula fugiu atemorizada quando perdeu um colar de ouro e esmeraldas da senhorita Leocádia, fil ha de seu senhor. Escravos do Dr. D om Francisco de Castro eD om M ariano M atute, ainda que não mencionassem surras ou açoites, Atanásio de los Santos e Andrés fizeram menção ao maltrato verbal e às permanentes ameaças que Ihes faziam. Assim pareceque, ainda queem $C$ artago a escravidão e possede escravos fossem fenômenos estendidos, onde não havia uma notável concentração de escravos eestes geralmente viviam em pequenos gruposfazendo trabal hos domésticos, o castigo com chicoteera uma prática corrente. É provável, também, queo paternalismo dos senhores, expressado através de certas condições devida, se combinassena forma natural com a severidadee sevícia dos castigos.

A segunda razão com que justificaram os escravos sua fuga foi o de estarem aborrecidos com seus senhores e não conseguir que fossem vendidosa outros, razão queé difícil apreciar, mas que devemos entender como o esgotamento das formas de convivência devido ao trato. Também, eisso é muito importante, as condições de vida nas quais os escravos não conseguiam acertos que permitissem ter um pecúlio e construir a esperança de poder comprar sua liberdade. Efetivamente, parece, não eram poucos os escravos que faziam acordos paga o pagamento de um jornal aos seus senhores, ou os que podiam destinar al guns dias da semana para si, especialmente buscando ouro nos ricos riachos da região. D efato, Prudêncio, sua esposa M artina e M anuela, de 25 anos, todos escravos de M ariano M atute, expuseram estas razões.

N o entanto, uma razão muito importante para a formação deste palenque parecehaver sido a busca de estabilidade para uma série de relações legítimas eilegítimas entre o grupo dosfugidos. Andrés, por exemplo, afirmou que seu patrão não permitia que sua esposa, uma mulata de nome Simona Lerma, vivesse na fazenda onde o mantinha trabalhando. Em tais circunstâncias, parece, Andrés manteve amizade ilícita com a escrava Paula, pois foi com esta com quem fugiu ecom quem dormiu os dias que durou o palenque. Inclusive, quando Ihe perguntaram sobrea intenção das mulhe res que os acompanharam, respondeu que era "estarse con ellos en mala amistad, cada una con el mancebo quetenían". Ainda assim Juan M anuel, 0 escravo castigado com 25 açoites por seu senhor, declarou haver levado 
consigo a mulata livre $M$ aria Avellaneda, de 16 anos, com quem fazia um ano e meio mantinha amizade ilícita. $M$ aria, que disseviver sob a tutela de sua mãe, deu como testemunho haver sido induzida violentamente por Juan $M$ anuel, com a idéia de levá-la primeiro a Cáli e logo às minas do C hoco. É provável que sua declaração buscasse atenuar seu castigo negando toda a responsabilidade. Além disso, sua mãenunca denunciou sua ausência, nem apareceu para depor no processo. I gualmente, Juana M aria Romero, livre, natural del bagué, de 19 anose deofício costureira e parteira, reconheceu que mantinha uma relação ilícita com o negro Simon, com o qual pretendia casamento. Ainda que declarasse que este a tinha tirado de casa, não manifestou quehouvesse sido com violência. Estes três casos permitem advertir que havia um motor explícito na fuga eera estabelecer uma comunidade livre das limitações quea sociedade colonial impunha para estabelecer os casais.

Efetivamente, Cartago tinha uma elevada população escrava e vivia uma intensa mestiçagem, porém, muitas destas uniões, especialmente as entravadas por escravos e livres, não eram reconhecidas e deviam existir na clandestinidade. $\mathrm{N}$ ão era aceita socialmente a união de uma moça livre, ainda que parda ou mulata epobre, com um negro escravo. Tampouco para o senhor do escravo era aceitável este tipo de união, por tudo o que contrariava sua posse e domínio. Estas uniões, num beco sem saída, só tinham como alternativa a fuga, decisão final e desesperada que podia trazer as piores conseqüências, como, em efeito, neste caso houve. 0 objetivo destes casais, eles mesmoso definiram como "poder vivir libremente", ou seja, seu romance, seu afeto. 0 juiz, inquieto sobre esseparticular, perguntou repetidamente como dormiam. M arcos, o filho de Prudêncio, respondeu: "que cada uno llevaba su mujer, con quienesseacostaban a dormir; el Andréscon la mulata Paula de D on Simón de Soto; Simón con Juana Romero libre; Juan $M$ anuel con $M$ aria Avellaneda también libre; y Vicente libre con su mamá M anuela...". M ais preciso, Atanasio declarou: "Q uea M aria Avellaneda la llevóJuan M anuel para dormir con ella; a Paula, Andrésnegro; a Juana Romero, Simón negro; y M anuela sela daba el capitán al confesante, quien no la quiso admitir, por lo quesela endosó a V i centeD osaga. Y queescierto que cada uno de los dicho dormían juntos como marido y mujer, unidos en todo". Além disso, acrescentou que o fim destas mulheres livres ali "era para estarse con 
ellos en mala amistad, cada una con el mancebo que tenía". Prudêncio, o chefe, esclareceu o papel de M anuela. Sobre isso disse: "Y quecon el motivo deir sola la negra $M$ anuela dispuso el declaranteleshiciera decomer, y atendiera a Vicente y al negro Atanasio porque no llevaban mujer para ello".

Richard Price, o grande especialista em palenques equilombos americanos, advertia que um dos pontos críticos destas sociedades era sua falta de mulheres, eos problemas que isso provocava. ${ }^{7}$ Isso explica a enorme clareza quetinha o negro Prudêncio ao buscar assegurar-se de mulheres. 0 outro aspecto significativo éo de que tudo apontava para a constituição de uma sociedade de família. Isso éobservável no fato de queduranteo tempo que durou o palenque, o grupo se dedicou a construir cabanas. N o momento queforam capturados estavam construindo a quarta, como querendo assegurar uma para cada casal ou grupo familiar.

De modo muito espontâneo alguns escravos declararam ao juiz que sua intenção era ir viver em liberdade. A escrava M anuela, por exemplo, disse: "el fin por el quesehuyó fue irsea vivir con los demás compañeros en $\mathrm{e}$ monte". A negra M aria M artina também coincidiu em que o propósito era "hacer susranchosy vivir allí". Simon, com confiança, afirmou quetinha a intenção debuscar ouro em alguma quebrada, para resgatar-see casar com sua concubina, e "ponerse en gracia de Dios". E a dubitativa M aria Avellaneda confessou que sempreescutou dos demais o desejo de "vivir libremente", ou seja, não cabe dúvida, que bem desde o início já na construção de sua pe quena fortaleza a idéia de liberdade tomava consciência em cada um. N ão obstante, é difícil afirmar que houve um plano real de atentar contra 0 sistema colonial e menos contra a ordem estabel ecida. É certo que alguns, especialmente Prudêncio e Andrés, fal avam em ocasiões de voltar à cidade pelos escravos de al gumas fazendas. Certamente, paisanos eamigos, alguns dos que estavam comprometidos no plano inicial e nunca chegaram à ramada do trapichena noitemarcada. D ado que os testemunhos dos escravos foram obtidos sob tortura, fica menos crível a pergunta que fizeram a todos os cimarrones sobre se era verdade que pretendiam voltar à cidade para exterminar todos os brancos e levar as mulheres. Típica obsessão colonial, em particular das sociedade escravistas, que revela mais o profundo temor, em ocasiões paranóico, dos senhores do quea verdadeira intenção dos escravos. Finalmente, a relação dos escravos com os indígenas uma vez mais se 
apresenta ambígua. A alusão aossupostosindígenas $C$ ocamas, rebeldes que os salvariam, era imaginária, sem nenhuma base real. 0 s C ocamasnão existiam. Assim mesmo, enquanto foram ajudados pela índia M aria e o índio Pedro Yara, seu al caide os entregou às autoridades brancas.

É bastante plausível a afirmação de alguns de que buscavam poder trabalhar nas minas para reunir o dinheiro de sua liberdade. Esta explicação, que podia tentar atenuar o rigor do castigo, encaixa na lógica dos escravos integrados ao sistema. Juana M aria Romero não teve dúvidas em observar que tomavam direção à boca do Rio 0 tún para buscar ouro "y pagar los corridosa susamos". M aría M artina, ainda assim, insistiu que "iban a buscar oroscon quélibertarsey mandar loscorridos", ou seja, no fundo, sua intenção era isolar-se da sociedade branca, convertendo-se em lavradores e mineiros independentes, como então o faziam inúmeros mestiços e mulatos livres.

\section{Cimarrones devotos}

Ao que parece, foi Prudêncio, líder e cabeça do grupo, o encarregado de reunir os elementos indispensáveis para o estabelecimento do palenque. Ao final, com os que partiram foram: uma escopeta, duas lanças, passadores, machetes, uma barra, uma enxada, uma pá e dois machados. Peças todas que lhes serviam para caçar, cultivar a terra e para defender-seem caso de um ataque. Todas pertenciam à fazenda de seu senhor, de ondeas tirou uma a uma. $\mathrm{N}$ o entanto, é muito interessante $\mathrm{o}$ fato de que também roubou e incorporou como peças importantes para a viagem distintas imagens de caráter religioso (chamada "efigies" no documento): um Jesus Cristo de metal, uma estampa de papel de N ossa Senhora de G uadalupe, outra estampa de N ossa Senhora de Belém, um quadrinho de Santa Bárbara, uma caixinha com uma efígie de Santa $G$ ertrudes (a queal guns chamaram Rita) e uma estampa de papel de São Ramón.

0 fato não passou despercebido para o juiz do caso que, no interrogatório, insistiu em perguntar com que propósito levavam ditas imagens. Com pequenas diferenças, todos responderam que para que os protegessem em seu empenho. Q ue para isso haviam feito um altarzinho e todas as manhãs e as noites rezavam. Q ue logo depois de rezar se "encomendaban a D ios", e que al gumas noites havia en cabeçado a oração do rosário o mulato 
Prudêncio, outras Simon e outras Paula, e os demais faziam o "coro". ${ }^{8}$ Estas imagens estavam associadas ao futuro do pequeno palenque, pois, como vários afirmaram, tinham planos de que, se sua intenção tivesse êxito, construiriam uma capela elevariam um sacerdote de $C$ artago que lhes desse missa.

A presença de imagens religiosas nos palenquese quilombos americanos é um fato inquietante. É compreensível que nos palenques dos séculos XVI eXVII, conformados principalmente por escravos recém-chegados da África, existissem e tomassem vigência os ritos e imagens religiosas ancestrais dos escravos. Também entreeles ocorreu um intenso sincretismo religioso, com ritos ecantos que combinavam o católico eo africano. Foi neste contexto, por exemplo, que, na Bahia, os escravos de palenquestransformaram Santo Antônio em protetor dos cimarrones. $\mathrm{N}$ ão foi este 0 caso dos escravos de Cartago. Sua crença religiosa católica não parecia ter discussão, e édifícil advertir formas de sincretismo. Ao menos o documento não o fala, contudo, especialistas no tema observam que as autoridades se ocupavam mais em buscar armas que em descobrir estas evidências, em ocasiões sem nenhuma materialidade.

Sabemos, sim, que os juizes duvidavam de sua real compreensão de certos atos defé. Por exemplo, se davam ao trabalho de explicar com todaa paciência que o que fossem dizer em suas declarações era feito sobre um grave juramento diante de D eus. Forma sutil, provavelmente, deatemorizar einduzir a verdade, contudo, éevidente queestes escravos haviam recebido uma mensagem que sabiam adaptar a suas necessidades. Suas rezas estavam dirigidas a pedir aos santos proteção eapoio para al can çar a felicidade. $N$ ão parecequea instrução religiosa promoveu neles uma cultura passivae conformista da escravidão. Sobreisso, EugeneG enoveseafirmou quea adesão dos escravos à religião dos senhores podia se converter em uma poderosa "defensa en contra de la deshumanización implícita en la esclavitud", com a qual os escravos, "al acercarsea una religión quesupuestamentedebía asegurar su complacencia y su docilidad, rechazaban la esencia de la esclavitud proyectan do sus propios derechos y valores como seres humanos". ${ }^{9}$

0 poderoso papel outorgado àsimagens religiosas, como a compreensão deque elasfaziam parte de uma comunidade cristã, explicam seu apego a elas e sua decisão de levá-las, inclusive roubadas. Sem a presença do Santo 
C risto eas distintas imagens pareceria que o palenque carecia de sentido ede futuro. C abe perguntar, ao menos, pela relação simbólica de Prudêncio, seu líder, que assumia como sacerdote nas orações que se faziam naquelas noites. Líder, guia e protetor, Prudêncio teve sempre presente a necessidade de levar C risto e as imagens de todos estes santos.

\section{Um mundo jamais imaginado}

A investigação sobre o palenquefrustrado revelou a existência subterrânea de uma organização dos escravos bastantechamativa. Como paródia, ou como sociedade alternativa, na própria cidade de C artago os escravos elegiam anualmente seu governo da mesma forma que os brancos. D esde algumas décadas antes, em cada primeiro de janeiro, os escravos faziam assembléias e votações às quais chamavam cabildo. N estas nomeavam vicerei, governador e tenente, ao modo do governo hispânico. M as também elegiam autoridades na forma das sociedades locais. N estas nomeavam AlferesReal, "alcaldeprovincial", "alguacil mayor", "depositario general", "regidores", "alcaldes ordinários", "alcaldes dela SantaH ermandad" e "alcal des pedáneos". ${ }^{10} \mathrm{C}$ ada ano as sessões se realizavam em casas distintas, especialmente nas dos nomeados. N osúltimosdoisanos sehaviam real izado na casa da negra D orotea Serna ena do negro Silvestre, este último, escravo deD om G regório Simon del Campo. N a cerimônia, com tom de solenidade, se fazia a entrega de "bastonesdepalo", aos Vice reise governadores por um período de doisanos, e aos demais de um ano. 0 uso dos bastões demonstrava aos demais sua dignidadeduranteo tempo da eleição.

A cerimônia também tinha um ar decididamente festivo. Q uem era nomeado devia custear osfestejose o que fosse consumido. Estabelecidas as dignidades se dava lugar "al bailey a la al egría", etambém a bebida (consumo deum refresco, segundo o documento). Também sefala que estas autoridades mantinham uma prisão com tronco para castigar aos que não obedeciam. Tratava-se, parece, da construção de outra cotidianidade, na qual se sentiam mais próximos eidentificados, ainda quenão haja dúvida de que o evento revela a existência de hierarquias e divisões no interior do mundo dos escravos e dos negros, pois aqueles que eram nomeados deveriam ter casa e meios para custear a celebração. 0 mulato Silvestre, quefoi chamado 
a declarar a raiz destas confissões, com o fim de simplificar a transcendência política destas reuniões, disseque eram "juegosdemuchachos". ${ }^{11}$ I gualmente, M artina afirmou que "lo hacían por juego y diversión y no se siguió daño a nadie". ${ }^{12}$

O significado destas reuniões não passou despercebido às autoridades. Para o juiz, tratava-se de uma perigosa suplantação da autoridade e uma ridicularização da ordem real. 0 mero fato de nomear vice reis e governadores Ihe parecia a semente de uma insurreição geral. Para os escravos, negros e mulatos, a recriação de al guns vínculos e sol idariedades, através da adaptação de um sistema de governo que lhes era estranho, mas não desconhecido. U ma influência precisa destes cabildos. ${ }^{13}$ Podemos ver no fato de quequase todos os escravos quefugiram participaram deles, al gunsjá havia dezenoveanos. Prudêncio, queera dos mais assíduos, fundou sualiderança, além disso, por ser capitão de campo de sua fazenda, razão que lhe permitia manter umahierarquia de prestígio entreosescravos defazendaedepois entre o grupo de cimarrones. Recorde-sea respeito quesetedos dez escravos provinham da mesma fazenda do $\mathrm{D}$ r. M ariano $\mathrm{M}$ atute. Cadaum dosmembros do grupo aceitou demaneira natural seu guia ehierarquia. A única lei que pereceria sefosse estabelecida era a deque, quem não quisesse obedecer efazer o que elemandasse, seriamelhor regressar.

\section{0 castigo}

0 processo levado a cabo contra os cimarrones de $C$ artago revelou as contradições da justiça colonial, entre a severidade e o rigor dos juízes da distante capital Santa Fée dos acessíveis al caides locais, e entreo poder dos fazendeiros regionais e a obediência dos fiscais. 0 s senhores, temerosos de perder seu patrimônio no caso de que os escravos fossem sentenciados a pena capital, buscaram atenuar a gravidade de sua ação. Seu defensor, D om Antônio Hurtado y Pontón, insistiu que jamais se havia consumado um delito contra "Ia lessa majestad divina y humana", e que "el afecto de ser libresa losesclavos leseslícito como connatural". ${ }^{14} O$ al caide local, interessado em acalmar os ânimos, pouco fazia para agilizar as diligências que conduziram à sentença. Um ano depois, o fiscal do caso, ofuscado com a apatia do alcaidee dosfuncionários locais, enviou uma relação do acontecido à Audi- 
ência, a qual, em forma severa e imediata, exigiu que os escravos fossem enviados à capital, fato que não pôde ocorrer tão rapidamente, pois a alcaidaria carecia de recursos para custear a comitiva de guardas que deveria ser conformada, gasto quea Audiência, uma vez mais, impôs aos senhores dos escravos.

O s escravos Prudêncio, Andrés, Simon, Juan M anuel e Atanásio foram tirados si gilosamente de suas celas às doze da noite do dia 16 de março de 1786. U ma vez reunidos no pátio da prisão, receberam uma manta, logo os acorrentaram e encaminharam a percorrer os trezentos quilômetros que separavam Cartago da capital. As condições da viagem e a miserável vida que encontraram na prisão Real de Santa Fé afetaram fatalmente a saúde destes escravos. Andrés, o mais vel ho, faleceu na prisão, eSimon, antes que saísse a sentença, já havia perdido a razão.

M udar a sede do processo permitiu aosjuízes da Audiência montar seu pequeno teatro de castigo e aplicar sua justiça exemplar. A punição e 0 suplício público aplicado sem esforço era uma autêntica pedagogia do medo para os demais. N o dia 3 denovembro de1787, Prudêncio foi sentenciado a duzentos açoites e oito anos de trabalho nas galeras de Cartagena; a Juan $M$ anuel eAtanásio duzentos açoitese seis anos de trabalho em Cartagena; e a Simon duzentos açoitese dois anos degaleras em Cartagena. "Y quedespués de cumplidas estas condenaciones, sus dueños dispusieren de ellos, con las precauciones de que no los pudieren internar en aquéllas provincias". ${ }^{15}$ Enquanto isso, na cidade de C artago, foi anunciada publicamente a sentença contra os demais acusados. 0 texto lido na praça, diante do povo que escutava com expectativa diz assim:

... hallo que debo condenar y condeno a Cristóbal mulato en cien azotes, porque habiendo sido sabedor de la fuga no dio aviso; a las negras $M$ artina y $M$ anuela, y a la mulata Paula en doscientos azotes; a la primera por haber sido en la fuga [ilegible], la tercera que ha hecho, y haber invitado con esta y sus insinuaciones a su marido Prudencio, que hizo de capitán. Y en ciento a cada una de las otras dos. En otros ciento al indio Pedro Yara, por el auxilio y aviso que les dio; en cincuenta a la india $M$ aria de los Arcos, por la acogida que les hizo; en otros cincuenta azotes a Juana M aría Romero y en veinticinco a M aria Avellaneda, por haber acompañado a los insinuados prófugos, y aunque por esto le correspondía 
igual pena, se les aminora con atención a la edad, por ser al tiempo del delito, aquella de dieciocho y ésta de dieciséis años. Por la misma consideración no se aplica pena alguna a los párvulos $M$ arcos y C ristóbal... ni al negrillo Juan José...pero para que les conste, se mantendrán presentes y el último maniatado y con soga de esparto al cuello, ínterin son azotados los que van nombrados. Para que éstos reciban lo que efectivamente les van asignados, se pondrán ocho postes en línea recta, cerca de la mitad de la plaza, y cada uno será atado al suyo, permaneciendo allí desde la hora en que se haga la ejecución hasta que se ponga el sol...y aunque no se considera peligro, ni remoto de algún insulto de los demás esclavos, porque no falte precaución, o sea más espectable el castigo, permanecerán de centinela, en cada una de las cuatro esquinas de la plaza, once hombres armados... renovando de hora en hora;... después será puesta a cada uno de los reos una calza con su ramal, que todo pese doce libras para los mayores y ocho para los dos menores y descubiertamente la lleven por tiempo de dos meses sin quitársela, so pena de que les sea aplicado a los amos o más personas que los coadyuvasen; en esta forma serán entregados los esclavos a sus amos, que tendrán prevenidas las dichas calzas con sus ramales, los dos indios al alcalde de su pueblo y las dichas Juana Romero y M aria Avellaneda, a sus madres... ${ }^{16}$

A severidade da condenação, seu caráter público, o castigo do corpo, a teatralidade buscada, sua falta de piedade a obrigar aos menores a observar 0 castigo de suas mães eao castigar uma idosa, tudo sublinha o sentido exemplar da justiça colonial. Com isso se buscava advertir e prevenir não somente aos outros escravos, mas também aos mestiços, mulatos, a todos os livres, inclusive aos brancos, de quea colaboração com todos os escravos que pretenderam a liberdade e que violaram a docilidade, seriam severamente castigados. Introduzia-se, assim, uma fratura na sociedade paternalista, permissiva com os cabildos de escravos, na que muitos val ores eram compartiIhados pelos escravos e seus senhores. N este caso, a mão da justiça do Rei atuou projetando os princípios que guiavam as reformas bourbônicas.

\section{Conclusão}

Sea cimarronaje era uma nostal gia daÁfrica, como diz Roger Bastide, o palenque de $\mathrm{C}$ artago pouco foi. $\mathrm{N}$ ão se tratou de uma insurreição de 
escravos boçais, recém-chegados das feitorias que rechaçavam seu translado ao N ovo M undo. Tratou-se, como vimos, de um movimento de escravos crioulos que buscaram viver sem as ameaças e coerções insi diosas do sistema escravista. I sso não quer dizer quebuscavam destruí-lo. 0 palenque, écerto, se constituía no sonho de viver em liberdade, isolados da sociedade branca. U ma comunidadena que cada família teria seu rancho ecultivaria sua terra. Provavelmenteseu ideal era de converter-se em pequenosagricultores, como tantos mestiços e mulatos o eram, mas também era o trabal har nas minas livremente para pagar sua liberdade, querendo com seu trabal ho restituir aos seus senhores o que perdiam com sua violenta ação, ou seja, não aspiravam a outra coisa que fazerem-se trabal hadores livres em uma sociedade de fronteiras abertas, ena que cada vez a legitimi dade eforça do sistema escravista se perdia.

Em suma, o palenque de C artago, como tantos outros movimentos, podeensinar-nosquea vida colonial esteve forjada por permanentes buscas de liberdade e autonomia. I sso é bastante claro no caso de escravos, mas também de indígenas, mestiços e mulatos. ${ }^{17} \mathrm{~A}$ relação de escravidão compreendia em forma tácita a possibilidade do castigo ao escravo. C onhecemos a existência de zonas de terror, onde a sevícia ea violência atuaram ao seu capricho. Por exemplo, plantações ou minas nas quais os senhores e capatazes tinham o domínio da lei e da justiça. N o entanto, parece, foram muitos mais os lugares on de o sistema de controle combinava o paternal ismo e o castigo. E foi nestes onde os protestos dos escravos e suas fugas foram mais freqüentes, quase como se expressassem em maior grau uma atitude contra os maus-tratos e uma esperança deliberdade. D efato, foram regiões, também, nas quais a lenta dissolução do sistema escravista iniciou por conceder dias para trabalhar livremente e encontrar seu sustento. O s escravos do palenque de C artago, como bem advertiu, em uma carta, D ona Petronila de la C ruz, esposa do fazendeiro M ariano H ormaza, só estavam adiantadosao seu tempo. ${ }^{18}$

Tradução: Tiago LuísG il 


\section{Notas}

${ }^{1}$ Esteestudo está baseado extensamente no processo judicial [AG N C, N egrosy Esclavos, Cauca, tomo 2, fols. 206-357]. 0 primeiro queidentificou esteevento foi JaimeJ aramillo U ribeem "Esclavosy señores en la sociedad colombiana del sigloXVIII", ACH SC , 1, Bogotá, 1963. $O$ utros autores comentaram distintosaspectos destemovimento: Anthony $M$ cfarlane, "Cimarronesy palenques en Colombia, sigloXVIII", em Revista H istoria y Espacio, Cáli, 14, 1990. Guido Barona, "La atrocidad dela justicia y el carácter ejemplarizantedela justicia del Rey. Popayán, siglo XVIII", 1990, inédito. H ermesTovar Pinzón, D euna chispa seforma una hoguera: esclavitud, insubordinación y liberación. Tunja, U PTC, 1992. Francisco Zuluagay Amparo Bermúdez, La protesta social en el suroccidentecolombiano, sigloXVIII. Cáli, U niversidad del Valle, 1997. M aisqueem sua ideologia ou em suas possíveis pretensões revolucionárias, nesteescrito procuro deter-mea observar as condições devida, as penúrias e os efêmeros gozos dosescravos de C artago.U maversão algo modificada do presenteartigo foi publicada no livro Tradicionesy conflictos. H istoriasdela vida cotidiana en M éxico eH ispanoamérica. M éxico: El Colegio deM éxico, 2005.

${ }^{2}$ Sobre o Código N egro Carolino (1784) e sua aplicação, ver M anuel Lucena Salmoral, Sangresobrepiel N egra. Q uito, Editorial Abya-Yala, 1994, pp. 204-206.

${ }^{3}$ Sobreo clássico Palmares podem ser lidos vários en saios contidos em João J oséR eis eFlávio dos Santos $\mathrm{G}$ omes (editores), Liberdade por um fio: H istória dos Q uilombosno Brasil. São Paulo, Companhia das Letras, 1996. Sobre o conhecido San Basilio dePalenquedeAquiles Escalantehá várias edições.

${ }^{4}$ Refere-seaos escravosfugidos [N ota do tradutor].

"Ver CarlosRamiro Bravo, "Papel dela esclavitud en la sociedad colonial cartagüeña", en Revista deCiencias H umanas, 2, N 0. 5, Sep. 1995, Pereira, p. 87.

60 rián Jiménez, EI Chocó: un paraíso del demonio. N ovita, Citará yel Baudó. Siglo XVIII. M edellín, U niversidad N acional, 2004, pp. 57-107.

${ }^{7}$ Richard Price (compilador), SociedadesCimarronas comunidadesesclavasrebeldesen las Amé ricas. M éxico, Siglo XXI, 1981, pp. 28-29.

${ }^{8} \mathrm{AGN}$ C, documento citado, fol. 215r.

${ }^{9}$ Eugene G enovese, Roll Jordan Roll: the world the savesmade. N ew York: Vintage Books, 1976, p. 7. Citado por Anthony M cfarlane, "Cimarrones y palenques en Colombia, siglo XVIII". En H istoria y Espacio, 14, junio de 1991, pp. 70-71.

${ }^{10}$ Aspas do tradutor. Para um maior aprofundamento no significado destes cargos, ver: LYN CH , John. Administración colonial española: 1782-1810. BuenosAires: Eudeba, 1967 [N ota do tradutor].

${ }^{11}$ AGN C, Ibid, fol. 283r.

${ }^{12} \mathrm{Ibid}, 220 \mathrm{v}$.

${ }^{13}$ Aspas do tradutor.

${ }^{14}$ Ibid. 328r. 
${ }^{15}$ Ibid. Fol. 414r.

${ }^{16} \mathrm{Ibid} .379-380$.

${ }^{17}$ Sobre isso, ver os sugestivos estudosincluídos no livro de D avid G. Sweet y G ary B. N ash, Lucha por la supervivencia en la América colonial. M éxico, Fondo de Cultura Económica, 1987.

${ }^{18} \mathrm{Ibid}$. fol. $328 \mathrm{v}$.

\section{RESUMO}

0 artigo analisa em um quilombo algumas das características das revoltas escravas na N ueva Granada do século XVII, com ênfase para as fugas e os castigos a escravos. Tais escravos postulavam viver como camponeses, como tantos mestiços livres de então. Palavras-chave: Palenque, cabildo de escravos, castigos exemplares, família escrava.

\section{ABSTRACT}

B ased on the case of $C$ artago palenque, this article analyses some of the characteristics of the saves uprisings occuped in the N ueva Granada kingdom during the XVII th Century. It explains the causes of the saves scape, their life circunstances in the farms and in the small town of Cartago. It also analyses the type of punishment exerted on these slaves.

Key words: Palenque, saves town council, severe punishment, save family.

(recebido em junho de 2005 e aprovado no mesmo mês) 